\title{
Carta Política do I Encontro Nacional de Mulheres Quilombolas (2014)
}

Coordenação Nacional de Articulação das Comunidades Negras Rurais Quilombolas

Em homenagem: Líder quilombola da cidade de Santa Luzia, PB, Maria do Céu Ferreira da Silva, 43 anos, não resistiu aos ferimentos por queimadura que foram causados pelo seu ex-marido. Maria do Céu era uma liderança valorosa, uma mulher generosa. Grande de alma mente e coração. Não media esforços para defender o povo quilombola e as mulheres negras que lutam por melhorias para a sua comunidade. Era uma mulher de coragem que usava a sua voz com empoderamento. Sem ter concluído a primeira fase do $1^{\circ} \mathrm{grau}$, fazia falas públicas e utilizava o microfone com habilidade.

Com 18 anos de existência, a Coordenação Nacional de Articulação das Comunidades Negras Rurais Quilombolas - CONAQ segue na luta diária pela demarcação dos territórios e soberania do povo Quilombola no País, no enfrentamento ao racismo institucional, ambiental, social, cultural e principalmente na vigília constante para que as Leis sejam cumpridas, a favor daqueles(as) que dela necessitam.

Não existe luta quilombola sem a participação feminina. Somos conhecedoras que nós, mulheres quilombolas, acumulamos ao longo da vida a função de ser mãe ou não, ser responsável pelo lar, cuidar da roça, dos animais, seja quebrando coco ou fazendo carvão, na labuta diária dos afazeres, no cuidar da família, trabalhando no comércio, na saúde, na educação, estudando. Enfim, acumulando funções na tarefa diária que é ser mulher. 
É neste sentido, que as mulheres quilombolas do Brasil, realizaram, em Brasília-DF, entre os dias 13 e 15 de maio de 2014, o I Encontro Nacional, com o objetivo de consolidar a luta pela terra, avaliar as políticas públicas e promover o diálogo entre as varias organizações quilombolas do Brasil. O Encontro representa para nós um passo importante no emponderamento das mulheres quilombolas, o qual se dá em suas mais variadas formas, gestos e manifestações, enfrentando a desigualdade racial, social, de gênero, geração e etnia.

Em torno de questões que são prioridades na nossa luta, nos reunimos em grupos de trabalho, intercambiamos experiências e elaboramos propostas para a construção e aprimoramento das políticas públicas, do ponto de vista das mulheres quilombolas. O apanhado das propostas segue em anexo ao documento final.

Dialogamos sobre o que queremos no processo de regularização fundiária. Foram muitos os relatos de conflitos em torno do território. Mesmo comunidades já tituladas sofrem com a ação de fazendeiros, empresas, órgãos do governo, dentre outros. Reivindicamos que o processo de regularização fundiária se desburocratize e seja mais ágil, pois essa morosidade implica no aumento dos conflitos. Além disso, percebemos que a execução da política nos estados tem problemas, devido à condução das superintendências regionais, que às vezes chegam a ficar ao lado dos fazendeiros. As mesas quilombolas nos estados precisam efetivamente funcionar e garantir uma representação quilombola com voz ativa nas superintendências regionais dos INCRA. Concluímos que não basta ter o território. Para viver livremente, com nossas tradições e cultura, precisamos de um modelo agroecológico sustentável. Nossas comunidades precisam também ser consultadas antes que se realize qualquer projeto que afete nossos territórios. Ou seja, a Convenção 169 da OIT deve ser colocada em prática. A adesão do Brasil a essa Convenção é fundamental para nós. Ressaltamos ainda a importância de combater outras tentativas de retrocesso na garantia de nossos direitos, como a Ação Direta de Inconstitucionalidade - Adi 3239, que questiona a constitucionalidade do Decreto 4887/2003 e a Proposta de Emenda Constitucional - PEC 
215, em tramitação no Congresso, sobre a demarcação e delimitação de terras indígenas e quilombolas.

No segundo grupo, discutimos o que entendemos como violência. Ela começa no fato da gente ser mulher. Essa é a primeira violência. É, então, o que nos tira do normal, gerando um sentimento dentro da gente. A violência pode ser física, moral, psicológica. Violências que acometem as mulheres quilombolas são experimentadas no próprio território, envolvendo: família, meio ambiente, religiosidade, racismo institucional. Temos que pensar em políticas públicas diferenciadas para mulheres quilombolas, que vão além da relação homem/mulher, que protejam as mulheres quilombolas em uma ação de despejo, por exemplo. A Lei Maria da Penha tem que se adequar ao contexto das mulheres quilombolas. A violência doméstica é um dos principais problemas nas nossas comunidades, mas não é o único. Uma coisa que nos parece fundamental é a proteção das lideranças femininas quilombolas que são ameaçadas em seu território. Diante disso, enumeramos os principais tipos de violência sofrida pelas mulheres quilombolas:

Impactos pelos grandes empreendimentos

Abuso sexual pelos trabalhadores das empreiteiras, fazendeiros e representantes políticos

\section{Drogas}

Poluição dos rios/ meio ambiente

Falta de proteção dos quilombos por parte do governo

Ausência de consulta prévia às comunidades quando se tratar de empreendimentos ou políticas que as afetem

Falta de ação que reduza os danos causados pelos projetos

Uso de agrotóxicos

Mudança nas formas de produção

Monocultura - soja/eucalipto

Violência física/doméstica

Abuso sexual de crianças 


\section{Discriminação}

\section{Racismo Institucional}

Quanto à saúde da mulher negra do campo, falamos sobre as dificuldades que enfrentamos na rede de saúde pública e no acesso aos programas de atendimento de saúde. Nas comunidades, faltam postos de saúde, estrutura adequada e profissionais capacitados. Não há atenção voltada aos problemas específicos que temos, como doença falciforme, hipertensão, diabetes, miomas, cânceres e glaucoma. Também não temos acesso ao pré-natal e a outras ações necessárias durante a gestação. Mesmo sabendo que temos direito às Unidades Básicas de Saúde - UBS e Núcleos de Apoio à Saúde da Família NASF, eles não chegam às nossas comunidades. Também falamos sobre as dificuldades dos profissionais da saúde respeitarem nossas práticas tradicionais de cuidado. As companheiras informaram que existe um meio de denunciar as violências que sofremos no atendimento de saúde. É o Disque 136 da Ouvidoria do Sistema Único de Saúde - SUS.

Identificamos que a manutenção de nossas lideranças dentro das comunidades é difícil, especialmente nossas jovens. Não há incentivos para permanência. Temos que sair do quilombo em busca de formação técnica profissionalizante. Com isso se enfraquece o vínculo com a comunidade e o sentido de pertencimento às raízes. Dessa forma discutimos questões sobre educação quilombola. Ressaltamos que as Diretrizes Curriculares Nacionais da Educação Escolar Quilombola são uma importante conquista. Cabe agora o desafio da implementação, que precisa respeitar a diversidade cultural de cada comunidade. Identificamos que somos muitas na área da educação. Reivindicamos trabalhar em nossas próprias comunidades, com apoio e estrutura adequadas. Quem estiver dando aula dentro das comunidades, precisa ser formado para isso. A Lei 10.639/2003 deve ser cumprida. Todo o país tem direito a conhecer nossa história, como importante contribuição do povo negro quilombola à formação do Brasil.

No campo da produção, observamos que a Declaração de Aptidão - DAP é um grande impasse para o acesso às políticas de fomen- 
to. Pensamos sobre as maneiras de ter acesso a DAP quilombola o mais rápido possível. O INCRA talvez não tenha estrutura para assumir essa demanda. Não há como pensar em fomento à produção das mulheres quilombolas, sem a garantia da titulação dos territórios. Estamos perdendo as linhas de crédito por falta do documento da terra. A burocracia do INCRA para titular territórios de quilombos deve diminuir. Quanto às políticas públicas de apoio à produção já existentes, temos demandas para todas as linhas do Programa de Organização Produtiva para Mulheres Rurais do MDA. Temos grupos produtivos de mulheres quilombolas, que podem configurar redes de produtoras e expor em feiras produtivas. Também precisamos de investimento para estruturação da produção.

Em nome de tantas mulheres quilombolas que se encontram privadas de sua liberdade, ameaçadas de morte e por todas que tombaram na luta, que tiveram seu sangue derramado pelo conflito agrário, pela violência doméstica; em nome de cada menina que nasce; em nome de cada mulher que assume o papel de transformar a sociedade racista, machista, patriarcal, é que construímos este momento para trocar experiências, histórias, recarregar as energias e continuar transformando o destino e a escrever as páginas da história das mulheres que têm memória, cultura e alma.

Precisamos desconstruir a ideia de que o poder é macho, branco e universitário. Precisamos nos empoderar! Ocupar espaços de poder político: eleger vereadoras, prefeitas, deputadas, senadoras quilombolas. Mulheres Quilombolas na labuta por: Igualdade, Justiça, Território e nenhum direito a menos.

Brasília, 15 de Maio de 2014

CONAQ 


\section{ANEXO \\ DOCUMENTO FINAL \\ I ENCONTRO NACIONAL DE MULHERES QUILOMBOLAS}

Mulheres quilombolas em defesa de nossos territórios

Queremos mais do que o território. Queremos o direito de viver de forma sustentável, agroecológica, com saúde e educação dignas.

Garantir a propriedade do território, como medida para acessar todas as demais políticas desenvolvidas para as comunidades quilombolas, assegurando no âmbito de estados e municípios investimentos nos quilombos reconhecidos, de acordo com as portarias federais vigentes.

Proteção dos territórios tradicionais quilombolas como patrimônio.

Um marco regulatório específico para as trabalhadoras rurais quilombolas, que permita acesso diferenciado e específico às políticas públicas, como a licença maternidade, auxílio doença e aposentadoria rural da Previdência Social, dentre outros, respeitando a especificidade quilombola.

Curso de Formação (à distância) sobre a legislação quilombola para permitir às comunidades compreenderem, acompanharem, monitorarem e fiscalizarem as políticas de reconhecimento, titulação e outras políticas públicas específicas para quilombos.

Estabelecimento de convênios do Incra Nacional com os estados que possuem legislação própria para acelerar os processos de regularização fundiária.

Efetivação do procedimento de consulta da Convenção 169 para garantir a regularização de territórios quilombolas onde há a sobreposição por áreas de conservação ambiental, empreendimentos de mineração, grandes barragens, dentre outros, garantindo a desafetação do território e o respeito ao artigo 216 da CF/88. 
Ações educacionais de formação política e de articulação das comunidades quilombolas para evitarem a divisão, cooptação, conflitos internos e não adesão às propostas da comunidade. Sugestão: com a participação de lideranças de comunidades já organizadas e de outras regiões para troca de experiências.

Criar mecanismos para responsabilização dos gestores públicos, quando da não aplicação dos recursos específicos para quilombos, como na educação, saúde, investimentos em casos de calamidades/ emergências, obras, dentre outros.

Garantir o reconhecimento de comunidades quilombolas por estados e municípios por meio de legislação própria.

Violência contra mulheres quilombolas

Criar uma rede de atendimento, proteção e defesa das mulheres quilombolas no enfrentamento à violência.

Ampliar e melhorar o serviço de proteção a mulheres quilombolas líderes, fazendo a conexão com outros programas/projetos, como o de combate a violência às mulheres do campo e da floresta, dentre outras iniciativas.

Garantir o direito de defesa dos quilombolas pela Defensoria Pública e Promotorias.

Adotar medidas de combate à discriminação e violência contra muIheres e crianças quilombolas.

Criação de núcleo de mulheres quilombolas na Secretaria de Políticas para as Mulheres.

Criação de Delegacias de Atendimento Especializado à Mulher em municípios que tenham comunidades remanescentes de quilombo.

Apoiar o fortalecimento institucional da CONAQ, das organizações estaduais e regionais, no tocante ao ativismo de mulheres quilombolas.

Saúde da mulher negra do campo 
Atendimento adequado às mulheres quilombolas na rede de saúde.

Estimular e garantir a participação de quilombolas em conselhos de saúde.

Fortalecer a utilização de fitoterápicos de uso tradicional.

Médicos generalistas e especialistas inseridos na rede de saúde.

Apoio e monitoramento do Ministério da Saúde para reforçar a implementação de programas de saúde específicos para doença falciforme, hipertensão, diabetes, doenças do aparelho genitourinário e ginecológicos (tratamento de miomas e cânceres) e glaucoma.

Campanhas educativas voltadas às questões de saúde da população quilombola e que estimulem a comunidade a denunciar problemas no atendimento de saúde.

Educação permanente para profissionais de saúde que trabalham em regiões quilombolas.

Favorecer a implantação de Unidades Básicas de Saúde - UBS e Núcleos de Apoio à Saúde da Família - NASF em regiões quilombolas, atendendo as necessidades de cada estado e região e /ou comunidade.

Combater a histerectomia em massa nos territórios quilombolas.

Organizar as associações comunitárias no sentido de reivindicar programas e ações em saúde quilombola.

Ampliar as ações e o acesso das comunidades quilombolas à seguridade social (saúde e assistência social).

Estimular e garantir a formação acadêmica de profissionais de saúde, em especialidades que tratem problemas relacionados a características raciais.

Estimular e garantir a implementação de programas de educação sexual e educação reprodutiva para adolescentes e jovens quilombolas.

Incluir postos de saúdes nas áreas quilombolas, desenvolvendo dentre outras, ações de prevenção de colo do útero e de doenças sexualmente transmissíveis.

Diagnóstico da saúde da população negra no Brasil. 
Garantir serviço de ambulância e ambulancha com pronto atendimento para comunidades quilombolas.

Mulheres quilombolas ocupam espaços de decisão e poder

Garantir recurso anual dentro das instituições que representam as comunidades quilombolas a nível nacional, estadual e municipal para formação política das mulheres quilombolas, incluindo o tema dos direitos das mulheres e enfatizando a importância da participação das mulheres na política dentro de suas comunidades, priorizando a juventude.

Incentivar as mulheres quilombolas a ocuparem cargos eletivos nos espaços executivo, legislativo e todos os espaços de decisão.

Retratar a importância da história dos quilombos no Brasil tendo como foco o protagonismo das mulheres quilombolas neste processo e de que maneira essas representações podem ajudar na compreensão das questões relativas às suas lutas individuais e coletivas pela liberdade e em prol dos direitos sociais.

Assegurar que as mulheres quilombolas tenham voz ativa em todas as instituições de governança, para que possam participar em igualdade com os homens no diálogo público e nas tomadas de decisão.

Criar/provocar um debate político a nível nacional, estadual e municipal com o tema: protagonismo das mulheres quilombolas no Brasil, em forma de decreto /lei que garanta um dia específico reconhecido em território nacional que caracterize as mulheres quilombolas no aspecto social, econômico, cultural e político deste país.

Garantir nos conselhos nacionais, estaduais e municipais a representação da mulher quilombola, especialmente nos conselhos da mulher.

Criar dentro dos órgãos públicos, pastas direcionadas para mulheres quilombolas coordenadas e executadas pelas mesmas.

Criar um plano de políticas públicas para as mulheres quilombolas nas três esferas do governo, considerando o protagonismo social, econômico, cultural dentro deste material. 
Constituição de um fórum nacional de mulheres quilombolas com encontro anuais.

Educação quilombola e o protagonismo feminino

Implantar a Educação Escolar Quilombola em todas as modalidades de ensino, levando em conta às Diretrizes Nacionais e a diversidade cultural da própria comunidade.

Que os estados e municípios implantem em seu projeto de lei o cargo professor quilombola, da própria comunidade.

Que o INCRA através do PRONERA atenda as demandas específicas dos quilombolas, priorizando territórios em fase de reconhecimento, em diálogo com lideranças estaduais e locais, durante todo processo de elaboração dos projetos, como forma de garantir que a juventude e mulheres quilombolas permaneçam em seus territórios.

Criação do Comitê de educação quilombola onde se discutam as propostas curriculares.

Seminários estaduais para professores quilombola com debate e formulação de propostas voltadas para inclusão de jovens.

Promoção de atividades de formação para jovens quilombolas dentro da comunidade com música, dança, estética negra, formação política, capoeira,e outros.

Capacitação para gestores da educação que atuam com comunidades quilombolas.

Maior acesso à informação sobre políticas publicas.

Que tenhamos uma licenciatura adaptada à realidade quilombola para professores.

A alimentação das escolas quilombolas deve ser conforme determinam as Diretrizes.

Cumprimento da Lei 12.960/13 - MEC, que impede o fechamento de escolas quilombolas. 
Intercambio entre jovens das comunidades quilombolas, para trocas de experiências.

Garantir a aplicação da lei 10.639/2003 e 11.645/2008 nos estados e municípios, com medidas severas e punitivas para casos de descumprimentos das leis.

O papel de mulheres quilombolas na produção

Agilizar e facilitar a emissão da DAP quilombola.

Titular urgentemente os territórios quilombolas no Brasil.

Garantir o efetivo funcionamento das mesas quilombolas nas Superintendências Regionais do INCRA nos estados.

Garantir assento e viabilidade de participação da CONAQ no comitê do PROGRAMA DE ORGANIZAÇÃO PRODUTIVA PARA MULHERES RURAIS do MDA.

Realizar chamada pública para assistência técnica e fomento, voltada para produção agrícola, artesanal e cultural de mulheres quilombolas, levando em conta a realidade diferenciada de cada comunidade quilombola. 